\title{
Pathogen Concentration Combined Solid-Phase PCR on Supercritical Angle Fluorescence Microlens Array for Multiplexed Detection of Invasive Nontyphoidal Salmonella Serovars
}

\author{
Aaydha Chidambara, Vinayaka; Ngo Anh, Tien ; Nguyen, Trieu; Bang, Dang Duong; Wolff, Anders
}

Published in:

Analytical Chemistry

Link to article, DOI:

10.1021/acs.analchem.9b04863

Publication date:

2020

Document Version

Peer reviewed version

Link back to DTU Orbit

Citation (APA):

Aaydha Chidambara, V., Ngo Anh, T., Nguyen, T., Bang, D. D., \& Wolff, A. (2020). Pathogen Concentration Combined Solid-Phase PCR on Supercritical Angle Fluorescence Microlens Array for Multiplexed Detection of Invasive Nontyphoidal Salmonella Serovars. Analytical Chemistry, 92(3), 2706-2713.

https://doi.org/10.1021/acs.analchem.9b04863

\section{General rights}

Copyright and moral rights for the publications made accessible in the public portal are retained by the authors and/or other copyright owners and it is a condition of accessing publications that users recognise and abide by the legal requirements associated with these rights.

- Users may download and print one copy of any publication from the public portal for the purpose of private study or research.

- You may not further distribute the material or use it for any profit-making activity or commercial gain

- You may freely distribute the URL identifying the publication in the public portal 


\section{Article}

\section{Pathogen concentration combined solid phase PCR on supercritical angle fluorescence microlens array for multiplexed detection of invasive non-typhoidal Salmonella serovars Vinayaka Aaydha, Tien Anh Ngo, Trieu Nguyen, Dang Duong Bang, and Anders Wolff} Anal. Chem., Just Accepted Manuscript • DOI: 10.1021/acs.analchem.9b04863 • Publication Date (Web): 06 Jan 2020

Downloaded from pubs.acs.org on January 8, 2020

\section{Just Accepted}

"Just Accepted" manuscripts have been peer-reviewed and accepted for publication. They are posted online prior to technical editing, formatting for publication and author proofing. The American Chemical Society provides "Just Accepted" as a service to the research community to expedite the dissemination of scientific material as soon as possible after acceptance. "Just Accepted" manuscripts appear in full in PDF format accompanied by an HTML abstract. "Just Accepted" manuscripts have been fully peer reviewed, but should not be considered the official version of record. They are citable by the Digital Object Identifier (DOI尺). "Just Accepted" is an optional service offered to authors. Therefore, the "Just Accepted" Web site may not include all articles that will be published in the journal. After a manuscript is technically edited and formatted, it will be removed from the "Just Accepted" Web site and published as an ASAP article. Note that technical editing may introduce minor changes to the manuscript text and/or graphics which could affect content, and all legal disclaimers and ethical guidelines that apply to the journal pertain. ACS cannot be held responsible for errors or consequences arising from the use of information contained in these "Just Accepted" manuscripts. 


\title{
Pathogen concentration combined solid phase PCR on supercritical angle fluorescence microlens array for multiplexed detection of invasive non-typhoidal Salmonella serovars
}

\author{
Aaydha C. Vinayaka ${ }^{1 *}$, Tien A. Ngo ${ }^{1 \S}$, Trieu Nguyen ${ }^{2}$, Dang D. Bang ${ }^{1}$ and Anders Wolff ${ }^{*}$ \\ ${ }^{1}$ Laboratory of Applied Micro and Nanotechnology (LAMINATE), Research Group for Food Microbiology and \\ Hygiene, National Food Institute, Technical University of Denmark, DK-2800 Lyngby, Denmark \\ ${ }^{2}$ Department of Biotechnology and Biomedicine, Technical University of Denmark, DK-2800 Lyngby, Denmark \\ ${ }^{\S}$ Current address: Vinmec Biobank, Vinmec HealthCare System, 458 Minhkhai, Vietnam
}

\begin{abstract}
Blood stream infections and invasive non-typhoidal Salmonellosis in particular remains a major health and economic burden worldwide. The complexity of blood matrices along with extremely low concentration of pathogens in blood pose great challenge for rapid and ultra-sensitive detection. Sample preparation has been the critical step that should provide blood matrix free sample with the targeted pathogen in the highest possible concentration. In this work, we addressed this challenge by combining magnetic bead based pathogen concentration and Solid-phase PCR (SP-PCR). The SP-PCR performed on a super critical angle fluorescence (SAF) microlens array embedded in a microchip enabled quick and accurate detection of low levels of Salmonella enterica serovar Typhimurium and Enteritidis in blood samples without culture enrichment. Protein AG-magnetic beads immobilized with antisalmonella antibody could efficiently concentrate both Salmonella serovars with a capturing efficiency $>95 \%$. Higher tolerance of Phusion hot start DNA polymerase to PCR inhibitors and its compatibility with protein AG-magnetic beads allowed the integration of SP-PCR. Analysis of Salmonella spiked blood samples with the SP-PCR resulted in a limit of detection (LoD) as low as $86 \mathrm{CFU} / \mathrm{mL}$ and 94 $\mathrm{CFU} / \mathrm{mL}$ for $S$. Typhimurium and $S$. Enteritidis respectively that could be attributed to the high fluorescence collection efficiency of the SAF microlens array. These combinations reduced the duration of analysis to less than 3 hours including sample preparation. This platform has the potential for its wide application as a high-throughput biosensor to analyze pathogens in clinical, food and environmental samples.
\end{abstract}


Bloodstream infections (BSI) caused by a wide variety of pathogens remain a significant burden in both high-income and lower-income countries. BSI accounts for $\sim 0.6$ million episodes in North America and about 1.2 million episodes in the European union (EU) resulting in roughly 86000 and 157000 deaths, respectively, every year ${ }^{1}$. Among BSI, invasive non-typhoidal Salmonella (iNTS) has gained immense attention as an emerging disease cluster ${ }^{2}$. Salmonella serovar Typhimurium and Enteritidis are identified as the major contributors accounting for an estimated 3.4 million episodes resulting in 0.6 million deaths in sub-Saharan Africa 2,3. The epidemiology and clinical manifestation of iNTS in Asia and South America are poorly described, however, an overall positive prevalence of $27.5 \%$ all together in Vietnam, Thailand, Indonesia and $16.2 \%$ in Malaysia were reported ${ }^{4,5}$. Inability of rapid detection in the early stages of infection remains the major cause of these morbidity and mortality ${ }^{6}$. Blood culturing, considered as gold standard technique, pose several challenge in the accurate diagnosis of BSI as it has low success rate $(30 \text { to } 40 \%)^{2}$. It often require more than 72 hours for complete identification of pathogens. In recent times, several multiplex-PCR techniques were reported and made commercially available for whole blood analysis (Table S1). However, these methods are not ideal for rapid point of care applications in high burden and resource-limited settings. Available diagnostic approaches for iNTS either lack clinically relevant sensitivity or have longer analysis time ${ }^{2}$.

In BSI, the number of recoverable bacteria are often in the range of 1 to $30 \mathrm{CFU} / \mathrm{mL}$ that is below the level of analytical sensitivity of many current PCR assays ${ }^{7}$. Blood matrices being highly complex in nature could adversely influence the assay sensitivity and reproducibility in bioanalytical methods. Therefore, sample preparation has become a critical step in improving blood matrix management and for obtaining better process throughput. In this direction, magnetic separation was reported as an ideal sample concentration method, which is compatible with the downstream molecular analysis ${ }^{8}$. Magnetic bead based strategy may simultaneously reduce the matrix effects and concentrate the pathogens thereby increasing analytical sensitivity and specificity ${ }^{8}$. Recently, matrix-assisted laser desorption/ionization time-of-fight mass spectrometry (MALDI-TOF MS) has been presented as an alternate method to direct molecular analysis of blood samples in BSI (Table S1). However, MALDI-TOF MS is not sensitive enough, thus, requiring long hours of blood culturing and a high abundance of bacteria for proper identification. As an improved approach, an immunoaffinity MALDI-TOF MS in combination with 
magnetic bead based sample concentration was reported previously ${ }^{9}$. This integrated MS fingerprinting could detect only 500 cells/ $\mathrm{mL}$ in blood serum and 8000 cells $/ \mathrm{mL}$ in whole blood. In order to address the challenges in direct blood sample analysis, SP-PCR in combination with magnetic bead based sample concentration is presented in this work as a promising strategy (Scheme 1).

In the SP-PCR, pathogen specific probes attached to a surface initiates solid phase amplification. In brief, initial thermal cycling generates amplicons of target genes in the reaction solution (liquid phase) that will binds to the attached pathogen specific probes on the solid surface if the probes match the DNA sequence. In the subsequent thermal cycling, amplification results in initial strand elongation and the extended probes act as templates for the second strand elongation generating new templates for the next round amplification. This result in the PCR products remain covalently attached to the solid support that can be detected by labelling one of the primers with fluorescent dye. In order to attain a superior fluorescence collection efficiency, the SP-PCR was demonstrated (with pure DNA) on a truncated coneshaped micro-lens array of SAF structures embedded in a polymer microchip ${ }^{10-12}$. However, the technique was not tested with real sample in the presence of complex matrix such as blood, food and fecal materials. SAF technology is based on the principle of asymmetric distribution of fluorescence near the interface of two media with different refractive indices. This results into emission of majority of the light into the higher refractive index medium. SAF micro-lens arrays exhibit two major advantages such as increased fluorescence collection efficiency and superior multiplexing capacity. In the present work, the SP-PCR was tested with spiked blood samples under multiplexed configuration in a polymer chip with integrated SAF micro-lens arrays. The feasibility of combined effect of magnetic bead based sample concentration and SP-PCR on SAF arrays to overcome challenges in direct blood sample analysis, the effects of blood matrix and rapid analysis were emphasized.

\section{EXPERIMENTAL SECTION}

\section{Sample concentration and direct PCR}

Salmonella Typhimurium ( $S$. Typhimurium) was concentrated from the whole blood using antisalmonella antibodies immobilized on the protein $\mathrm{A} / \mathrm{G}$ magnetic beads as described in Supporting Information. Serial 10-fold dilutions of $S$. Typhimurium cells were prepared in $300 \mu \mathrm{L}$ of bovine blood stabilized with citrate to attain a final concentrations ranging from $2 \mathrm{CFU}$ to $1.6 \times 10^{4} \mathrm{CFU}$. The spiked 
pathogens were captured with $10 \mu \mathrm{g}$ of Ab-bead conjugate and the beads were separated from the blood. Further, the volume of the blood was made up to $1 \mathrm{~mL}$ with $10 \mathrm{mM}$ PBST and $100 \mu \mathrm{L}$ of this blood solution was plated directly on BA plates in duplicates for determining bacterial count. The bacterial colonies (CFU) were counted after an overnight incubation at $37{ }^{\circ} \mathrm{C}$ and the efficiency of $\mathrm{Ab}$-bead to capture Salmonella at different spiking concentrations was calculated.

In order to examine the influence of the whole blood matrix on the direct PCR, various blood dilutions were prepared by mixing bovine blood with $10 \mathrm{mM}$ PBST to obtain 40\% (400 $\mu \mathrm{L}$ blood in $1 \mathrm{~mL}$ ), 60\% $(600 \mu \mathrm{L}$ blood in $1 \mathrm{~mL})$ and $80 \%(800 \mu \mathrm{L}$ blood in $1 \mathrm{~mL})$ blood concentrations. These blood dilutions and $10 \mathrm{mM}$ PBST (as a negative matrix control) were spiked with $100 \mu \mathrm{L}$ of $S$. Typhimurium $\left(7.4 \times 10^{3}\right.$ CFU). The spiked $S$. Typhimurium was captured using $10 \mu \mathrm{g}$ of Ab-bead conjugate and magnetically concentrated. The beads were washed and direct PCR was performed using Phusion Blood Direct PCR Kit (Thermo Scientific) as described in Supporting Information. The amplified PCR products were confirmed by $2 \%$ agarose gel electrophoresis.

\section{Effect of blood lysis on the pathogen capturing efficiency and direct PCR}

Blood lysis as an option to improve the pathogen capturing efficiency of Ab-bead conjugate and performance of the direct PCR was studied. Initially, viability of the $S$. Typhimurium was tested in the presence of blood lysis agents. Five hundred $\mu \mathrm{L}$ of bovine blood was spiked with $100 \mu \mathrm{L}$ of $S$. Typhimurium (755 CFU as estimated by culture and colony counting). The spiked blood was mixed with $50 \mu \mathrm{L}$ of Saponin 13,14 to obtain a final concentration of $0.1 \%, 0.5 \%, 1 \%, 2.5 \%$ and $5 \%$ in separate experiments and incubated at room temperature for 2 minutes by gentle mixing. Further, $50 \mu \mathrm{L}$ of CHAPS ${ }^{15}$ was added to obtain a final concentration of $1 \%$. After incubation for 2 minutes at room temperature by gentle mixing, volume of the solutions was adjusted to $1 \mathrm{~mL}$ with $10 \mathrm{mM}$ PBST. Similar experiment was conducted in PBS spiked with $S$. Typhimurium (755 CFU) and treated with respective concentration of Saponin and $1 \%$ CHAPS as a control. The samples were incubated at $37{ }^{\circ} \mathrm{C}$ for 30 minutes and $100 \mu \mathrm{L}$ of each reaction solution were plated directly on BA plates in duplicates. Bacterial colonies (CFU) were determined after an overnight incubation at $37^{\circ} \mathrm{C}$ and the viability of $S$. Typhimurium was calculated. 
In order to examine the effect of lysed blood matrix components on the direct PCR, $200 \mu \mathrm{L}, 400 \mu \mathrm{L}$ and $600 \mu \mathrm{L}$ of sterile bovine blood was lysed with $2 \%$ Saponin and 1\% CHAPS as described above. Volume of the lysed blood samples was adjusted to $800 \mu \mathrm{L}$ with $10 \mathrm{mM}$ PBST and mixed with $200 \mu \mathrm{L}$ of $\mathrm{Ab}$-bead conjugate $(10 \mu \mathrm{g})$. The samples were incubated at $37^{\circ} \mathrm{C}$ in a bench-top rotator mixer for 30 minutes. The beads were magnetically concentrated and transferred to PCR tubes. An overnight culture of $S$. Typhimurium $\left(3.5 \times 10^{4} \mathrm{CFU}\right.$ in $\left.4 \mu \mathrm{L}\right)$ were added to these Ab-bead conjugates concentrated from the lysed sterile blood along with $6 \mu \mathrm{L}$ of a direct PCR mixture and direct PCR was performed. The amplified PCR products were confirmed by $2 \%$ agarose gel electrophoresis and assessed by ImageJ software (https://imagej.nih.gov/ij/) for comparison.

Sensitivity and LoD of the direct PCR in the blood was evaluated by spiking $1 \mathrm{~mL}$ of bovine blood with $100 \mu \mathrm{L}$ of $S$. Typhimurium from a 10-fold serial dilution prepared from a stock culture $\left(\mathrm{O}^{\mathrm{D}} \mathrm{D}_{600}=\right.$ $\sim 0.8$ ) to attain a final concentration gradient from $8 \mathrm{CFU}$ to $8 \times 10^{4} \mathrm{CFU} / \mathrm{mL}$ of blood. The spiked blood was lysed as described above and the reaction volume was adjusted to $1.8 \mathrm{~mL}$ with $10 \mathrm{mM}$ PBST. The spiked pathogens were concentrated with $10 \mu \mathrm{g}$ of Ab-bead conjugate $(200 \mu \mathrm{L})$ and direct PCR was performed.

\section{Multiplexed SP-PCR}

Fabrication and characterization of injection molded SAF microlens array chip. The polymer microchip with SAF microlens array was fabricated by injection molding (Engel Victory 80/45 Tech, PA, USA) as described previously ${ }^{10,11}$. In brief, a molding insert was initially milled in hard aluminium (alloy 2017, MetalCentret, Denmark) using a computer controlled micro-milling system (Folken Ind., Glendale, California, USA). A $60^{\circ}$ engraving tip (DIXI 7006, Le Locle, Switzerland) was used to mill the truncated cone shaped SAF arrays. The metal insert was polished (metal polish, Autosol, USA) to get a smooth surface. Dimension and surface roughness of the SAF structure were measured using scanning electron microscopy (SEM, Quanta 200 FEI) and PLu Neox 3D optical profiler (Sensorfar, USA) respectively. Further, the polished aluminium insert was used to fabricate microchip having 4 reaction chambers (with 32 truncated cone shaped SAF structures in each chamber) in cyclic polyolefin copolymer (COC) (TOPAS 5013-10, Topas Advanced Polymers GmbH, Germany) by injection molding. 
Detection of Salmonella subtypes with SP-PCR. Multiplexed solid phase amplification was performed in SAF microlens array microchip for detecting Salmonella spp. Before SP-PCR, reaction chamber of the microchip containing target specific surface probes immobilized SAF arrays was treated with $25 \mu \mathrm{L}$ of $0.1 \times$ SSC buffer containing $0.25 \%$ bovine serum albumin (BSA) for 30 min at room temperature. Later, the chamber was rinsed with Millli-Q water and dried at room temperature followed by sealing the chamber with thermostable, PCR compatible optical adhesive cover (Applied Biosystems, USA). Ab-bead-Salmonella Typhimurium complex and Ab-bead-Salmonella Enteritidis complex that were obtained after concentrating spiked $S$. Typhimurium $\left(4.50 \times 10^{4} \mathrm{CFU}\right)$ and $S$. Enteritidis $\left(4.54 \times 10^{4}\right.$ CFU), respectively, from $10 \mathrm{mM}$ PBST in separate experiments were re-suspended back in $10 \mu \mathrm{L}$ of $1 \mathrm{x}$ Phusion blood PCR buffer. The beads were transferred carefully into separate reaction chambers of the microchip. Later, solid phase amplification was performed with $15 \mu \mathrm{L}$ of PCR mixture containing 400 $\mathrm{nM}$ of hilA (hyperinvasive locus A) forward and $1600 \mathrm{nM}$ of hilA reverse primers, $200 \mathrm{nM}$ of $s d f$ (Salmonella difference fragment) forward and $800 \mathrm{nM}$ of $s d f$ reverse primers, $600 \mathrm{nM}$ of fliC (Flagellin i-antigen) forward and $2400 \mathrm{nM}$ of $f l i$ C reverse primer (Table S2), $400 \mathrm{ng}$ BSA, $0.05 \mathrm{U} / \mu \mathrm{L}$ Phusion blood II DNA polymerase and 1x Phusion blood PCR buffer. The SP-PCR was conducted in a ProFlexTM 2x flat PCR system (Thermo Fisher Scientific). The PCR conditions were $94{ }^{\circ} \mathrm{C}$ for 5 min following by 20 cycles of $94{ }^{\circ} \mathrm{C}$ for $10 \mathrm{~s}, 60^{\circ} \mathrm{C}$ for $20 \mathrm{~s}, 72{ }^{\circ} \mathrm{C}$ for $20 \mathrm{~s}$ and another 15 cycles of $94{ }^{\circ} \mathrm{C}$ for $10 \mathrm{~s}, 65^{\circ} \mathrm{C}$ for $20 \mathrm{~s}$ and $72{ }^{\circ} \mathrm{C}$ for $20 \mathrm{~s}$. After the reaction, the chambers were washed with 1x SSC followed by $1 \mathrm{x}$ SSC containing 1\% Tween-20 for $10 \mathrm{~s}$ and 2 times with Milli-Q water for $20 \mathrm{~s}$. The reaction chambers were dried at room temperature before scanning the chip for data analysis.

Analysis of Salmonella spiked blood samples. Bovine blood stabilized with citrate (1 mL) was spiked with $S$. Typhimurium and $S$. Enteritidis $\left(\sim 7 \times 10^{4} \mathrm{CFU}\right.$ of each) in separate experiments and lysed as mentioned above. The spiked pathogens were concentrated using $10 \mu \mathrm{g}$ of Ab-bead conjugate after incubating at $37^{\circ} \mathrm{C}$ in a bench-top rotator mixer for 30 minutes. The concentrated beads were washed and transferred to reaction chambers in a microchip and SP-PCR was performed as mentioned above. After amplification, the reaction mixture was decanted from the chambers and the amplified PCR products left in the liquid phase were confirmed by $2 \%$ agarose gel electrophoresis. The reaction chambers were washed thoroughly as optimized above and dried at room temperature before scanning the chambers for fluorescence imaging. 
Sensitivity and LoD of the SP-PCR in the blood was evaluated by spiking $1 \mathrm{~mL}$ of anonymous healthy human volunteer blood with $S$. Typhimurium and $S$. Enteritidis in separate experiments. The blood was spiked separately with $100 \mu \mathrm{L}$ of $S$. Typhimurium or $S$. Enteritidis from a 10-fold serial dilution prepared from a stock culture $\left(\mathrm{O}^{\mathrm{D}} \mathrm{D}_{600}=\sim 0.8\right.$ for each) to attain a final concentration gradient from $10^{1} \mathrm{CFU} / \mathrm{mL}$ to $10^{3} \mathrm{CFU} / \mathrm{mL}$ of blood. The spiked blood was lysed and the pathogens were concentrated using $10 \mu \mathrm{g}$ of Ab-bead conjugate and SP-PCR was performed as described above. After the reaction, reaction mixture (liquid phase) was analyzed by $2 \%$ agarose gel electrophoresis while the SAF structures in the microchip (solid phase) was analyzed using microarray scanner to confirm the amplifications.

Image acquisition and analysis. After the solid phase amplification, the microchip was scanned using a BioAnalyzer 4F/4S scanner (LaVision BioTec GmbH, Bielefeld, Germany) with 200-ms exposure time. The captured image was analyzed using ImageJ software ${ }^{16}$ and the fluorescence intensity of Cy3 dye was quantified. For precise quantification of fluorescence, area under the SAF structure of the scanned image was restricted with a circle adjusted to the size of the SAF structure. Subsequently, the mean value of grey levels of the pixels inside the circle covering the fluorescent spot was calculated. The mean value of signals of the pixels inside the circle in an area of the microchip without SAF structure was considered as background 1 . This background 1 was subtracted from the mean $(n=3)$ signal under the area of the circle on the SAF structure without any immobilized surface probes. This signal was eventually considered as background 2. A signal to noise ratio (SNR) in this study was defined as the mean $(n=6)$ signal intensity of the SAF structures after amplification. The background 2 was subtracted from this mean signal intensity and the resulting value was divided by the standard deviation (SD) of the background 2. The LoD of the assay was estimated at an average SNR of triplicates of lowest bacterial concentration tested ${ }^{17}$.

\section{RESULTS AND DISCUSSION}

\section{Effect of magnetic beads on the efficiency and sensitivity of direct PCR method}

Direct PCR bypass the pre-PCR DNA extraction/purification steps. It opens a way for the integration with pre-pathogen concentration technique that may be the best efficient approach to overcome matrix effects in molecular diagnostics ${ }^{8}$. Hence, a combined approach was adapted, in this study, to concentrate Salmonella spp., from spiked blood samples followed by direct PCR. Protein A/G capped magnetic beads 
were used to immobilize anti-salmonella antibodies. Affinity of protein A/G for the Fc (Fragment crystallizable) domain of an antibody provides unidirectional orientation to immobilized antibodies. This strategy of immobilization places antibodies in an ideal position for enhanced antigen recognition ${ }^{18}$. In our previous study ${ }^{8}$, the effect of magnetic beads on the efficiency and sensitivity of direct PCR method for the detection of $S$. Typhimurium was discussed in detail. It was found in our previous study that protein $\mathrm{A} / \mathrm{G}$ capped magnetic bead $(1.254 \mu \mathrm{M})$ enable an antibody immobilization efficiency up to $\sim 98 \%$. Direct PCR conducted in the presence of Ab-bead conjugates resulted in a specific amplification product of $225 \mathrm{bp}$ of the hilA gene. Ab-bead conjugates did not show any inhibitory effect on the direct PCR even at concentration of $4.8 \times 10^{7}$ beads per $10 \mu \mathrm{L}$ of PCR reaction. Finally, $10 \mu \mathrm{g}$ of Ab-bead conjugate ( $4.8 \times 10^{6}$ beads) having 598 ng of immobilized antibody in total was used in the Salmonella capturing experiments. The magnetic bead-based approach had a capturing efficiency of $>95 \%$ for $S$. Typhimurium. Integrated immuno-magnetic direct PCR method had a relative PCR efficiency of $\sim 92 \%$ resulting in a limit of detection (LoD) of $\sim 2 \mathrm{CFU} / \mathrm{mL}$ of the spiked food sample ${ }^{8}$.

In the present study, the $\mathrm{Ab}$ conjugated beads were used to capture $S$. Enteritidis also and noticed similar capturing efficiency. The antibody used in this study had a polyvalent specificity for Salmonella " $O$ " (somatic lipopolysaccharide antigen) and " $H$ " (flagellar protein) antigens of both $S$. Typhimurium and $S$. Enteritidis. This is because the immunogen used to generate antibody was a mixture of $S$. Enteriditis, $S$. Typhimurium and $S$. Heidelburg as specified by the supplier. Therefore, it was possible to concentrate both serovars at a concentration lesser than $10 \mathrm{CFU} / \mathrm{mL}$ from PBS. Accordingly, the direct PCR conducted on these pathogen concentrated beads was positive at a concentration as low as 9 $\mathrm{CFU} / \mathrm{mL}$ and $7 \mathrm{CFU} / \mathrm{mL}$ for $S$. Typhimurium and $S$. Enteritidis respectively (Figure1).

\section{Studies on the Salmonella spiked blood samples}

Effect of blood dilutions on the capturing efficiency. The developed integrated immuno-magnetic direct PCR method was used to test blood samples spiked with $S$. Typhimurium. Initially, citrate stabilized bovine blood was used as matrix to optimize the assay. Ab-bead conjugate could concentrate the Salmonella with a capturing efficiency in the range $75-80 \%$ as revealed by culture and colony counting method. However, the direct PCR performed on these beads was not successful probably due to PCR inhibition. Repeated washings of the Ab-bead conjugate with PBST after capturing $S$. 
Typhimurium did not overcome the effect of inhibitors from the blood. Therefore, dilution of blood as a simple strategy to reduce the effects of PCR inhibitors ${ }^{19}$ was attempted. Dilution of blood had a positive effect on the performance of the direct PCR. The target DNA amplification was better for the samples concentrated at higher blood dilutions as revealed by gel electrophoresis (Figure S1). However, QPCR did not reveal any promising results because of possible quenching of SYBR fluorescence.

Studies on the blood lysis and direct PCR sensitivity. Blood lysis was studied as an option to avoid non-specific adsorption of blood cells on the magnetic beads. Hemoglobin, a well-known PCR inhibitor, may interfere with the performance of the direct PCR either by decreasing the polymerase efficiency or by quenching fluorescence of the DNA intercalating dye. Blood cell lysis could provide an ideal condition to washout excess blood matrix and non-specifically adsorbed inhibitors. Researchers have studied Saponin ${ }^{13,14}$ and CHAPS ${ }^{15}$ as blood cell lysing agents separately. Nevertheless, it is important to consider maintaining viability and intactness of the bacterial cells while lysing blood cells efficiently. It was found, in this study, that $1-2 \%$ of Saponin in combination with $1 \%$ CHAPS were ideal concentrations to lyse the blood cells completely at which the viability of spiked Salmonella spp. was $\sim 90 \%$ (Table S3). Gel electrophoresis confirmed the amplification of hilA gene from immunomagnetically concentrated $S$. Typhimurium as low as $820 \mathrm{CFU}$ in the spiked blood samples (Figure S2). However, SYBR fluorescence remained quenched that made it difficult to identify the true amplification in QPCR at lower concentrations resulting in false negative results (Figure S3). The relative PCR efficiency was $\sim 85 \%$ (Figure S4) in the spiked blood samples while it was $\sim 92 \%$ in PBS ${ }^{8}$.

Direct PCR experiments were performed using Phusion blood direct PCR Kit (Thermo Fisher Scientific). The kit is designed to perform PCR directly from whole blood without prior DNA extraction or sample pre-treatment. The Phusion hot start II high-fidelity DNA polymerase used in this kit is a modified polymerase that exhibits extremely high resistance to inhibitors found in blood. High-fidelity, catalytic activity and stability of this enzyme is due to its fusion with a double-strand DNA-binding domain (Sso7d) that improves the performance of the polymerase by guiding negative supercoiling ${ }^{20}$. However, the recommended concentration of blood allowed in a PCR reaction using this kit is 5\% according to the manufacturer so as to limit the concentrations of inhibitors during PCR. It is important to note that in most of the early infection cases the microbial load can be lesser than $1 \mathrm{CFU} / \mathrm{mL}$ in blood. This makes it difficult to directly analyze blood samples without concentration or enrichment of the 
targets 7 . Hence, magnetic bead was used to concentrate Salmonella spp. and to get rid of inhibitors from blood matrix. In general, an interference in the QPCR may occur as a result of either polymerase inhibition, nucleotide inhibition or quenching of fluorescence ${ }^{21,22}$. The Pierce protein $A / G$ magnetic beads do not have any adverse effect on the polymerase activity because of their proprietary double-shell design (Protein Biology Application Notes, https://www.thermofisher.com). Their compatibility with direct PCR was studied and reported previously by our group ${ }^{8}$. However, samples with strong background color are known to interfere with fluorescence detection in QPCR by simply masking or obstructing the fluorescence ${ }^{22,23}$. Inherent brownish color of the protein AG magnetic bead had very low interference on the SYBR green fluorescence during the direct PCR. There was $\sim 8-9 \%$ reduction in the SYBR green fluorescence resulting in a delay of approximately 1.5 cycles to reach the threshold fluorescence in the presence of $10 \mu \mathrm{g}$ of Ab-bead conjugate. This observation was also reported in our previous study ${ }^{8}$. On the other hand, hemoglobin in the blood may act as a strong inhibitor of both polymerase activity and the fluorescence in QPCR. It was reported that whole blood decreases amplification efficiency and cause severe static quenching of DNA intercalating dyes such as SYBR, EvaGreen, ROX and probably others. Binding of free dye molecules in the central cavity of hemoglobin was reported to be a possible mechanism behind these static quenching effects (Sidstedt et al., 2018). This mechanism seems possible as hemoglobin has strong absorption between $500 \mathrm{~nm}$ and $600 \mathrm{~nm}{ }^{25}$ that may spectrally overlap with the emission spectra of SYBR dye $(522 \mathrm{~nm})$. During magnetic concentration of targets from the blood, the possibility of co-concentration of iron containing hemoglobin along with the beads may not be completely ruled out because the magnetic beads create local magnetic field. Successful amplification as revealed by gel electrophoresis and failed to detect amplicons in QPCR supports this theory (Figure S2 and S3). Thus, inconsistency in the detection of S. Typhimurium directly from spiked blood samples was attributed to following factors. First, possible co-concentration of hemoglobin along with $S$. Typhimurium from the lysed blood samples during magnetic concentration; Second, quenching of SYBR fluorescence resulting in failed detection of amplicons; Third, the Phusion polymerase failed to overcome potential PCR inhibitors of the blood samples as the blood matrix in the assay were much beyond the recommended blood volume in the reaction. 


\section{Studies on the multiplexed SP-PCR}

SP-PCR has become increasingly popular in recent times as an alternate strategy for molecular analysis. Performing SP-PCR on a SAF microlens array structure minimizes undesirable interactions and enables multiplexing capability due to the spatial separation of amplicons. Polymer SAF arrays also increases assay sensitivity because of the principle of collimation of the emitted fluorescent light at supercritical angle thereby enhancing the fluorescence collection efficiency. It was reported that $\sim 1$ to 13 fluorophores (per $\left.\mu \mathrm{m}^{2}\right)$ can be detected with truncated cone-shaped SAF structure $\left(60^{\circ}\right.$ angle that ensure total internal reflection) resulting in 36-40 folds increase in the sensitivity ${ }^{10,11}$. It is worth mentioning here that fluorophores conjugated to the detector probes are not susceptible to quenchers unlike free DNA intercalating dyes ${ }^{24}$. Therefore, the SP-PCR on integrated SAF micro-array structures in a lab-on-a-chip platform is an ideal technique to integrate with magnetic bead based sample concentration to overcome inhibition from blood matrix components.

\section{Characterization and application of SAF integrated polymeric chip for Salmonella detection.} Multiplexed solid phase amplification was performed in a polymer microchip containing SAF microlens array structures. These microchips were fabricated as reported previously ${ }^{11}$. Prior to SP-PCR, the microchip was characterized to confirm the fabrication reproducibility and quality of the SAF structures. The reaction chamber in the microchip had a depth of $500 \mu \mathrm{m}$ with a holding capacity of $23-25 \mu \mathrm{L}$ reaction volume that contributed to overcome possible bubble formation while loading the samples and enabled proper distribution of the samples in the chip. There were 32 identical SAF structures aligned inside the chamber in a pattern $(8 \times 4)$ at an inter distance of $0.625 \mu \mathrm{m}$ between the structures (Figure $2 \mathrm{a})$. These SAF structures were $\sim 140 \mu \mathrm{m}$ wider at the top surface and $\sim 485 \mu \mathrm{m}$ wider at the bottom with mean surface roughness of $\sim 161 \mathrm{~nm}$ (Figure $2 \mathrm{~b}$ and $2 \mathrm{c}$ and Figure S5).

In order to initiate solid phase amplification DNA probes targeting the hilA, sdf, and fliC genes were directly immobilized on these SAF microlens arrays using UV-induced immobilization technique without any surface modification (Figure 3a). The hilA gene located in Salmonella pathogenicity island (SPI-1) is responsible for the regulation of the Type III secretion system (T3SS) in cell invasion. HilA gene being specific for Salmonella enterica sub-species Enterica can recognize 57 different Salmonella strains in general ${ }^{26}$. On the other hand, the fliC gene targets i-antigen specific phase 1 flagellin in $S$. 
Typhimurium ${ }^{27,28}$ and $s d f$ (Salmonella difference fragment) is specific to $S$. Enteritidis ${ }^{29-31}$. The SPPCR conducted on magnetically concentrated $S$. Typhimurium and $S$. Enteritidis in the microchip with SAF structures revealed distinct fluorescence patterns wherein, amplification of hilA gene confirmed Salmonella spp. in general and amplification of $f l i \mathrm{C}$ and $s d f$ genes differentiated serovar Typhimurium from serovar Enteritidis respectively (Figure 3b and 3c). Amplification of specific combinations of these targeting genes made it possible to detect Salmonella at serovar level in a multiplexed configuration. Absence of detectable fluorescence signals from the SAF structures with negative control confirmed the specificity and accuracy of this technique. In the left out reaction liquid, two specific amplicons of 238 bp of the hilA gene (between the position $1043 \mathrm{bp}$ and $1281 \mathrm{bp}$ ) and $436 \mathrm{bp}$ of the fliC gene (between the position $794 \mathrm{bp}$ and $1230 \mathrm{bp}$ ) were obtained for $S$. Typhimurium. Similarly, a combination of two specific amplicons of $238 \mathrm{bp}$ of the hilA gene and $311 \mathrm{bp}$ of the $s d f$ gene (between the position $20 \mathrm{bp}$ and $331 \mathrm{bp)}$ were obtained for $S$. Enteritidis. Electrophoresis gel image confirmed these specific amplicons as well as the absence of any other amplified products inferring specificity of the primers for the target gene (Figure 3d). In principle, the amplified products of the liquid phase reaction serve as templates for SP-PCR and hence, the results were in accordance with solid phase amplification results. In the SP-PCR, primers were used in different ratios in order to reduce the competition between the unbound primers in the liquid phase and the solid-phase probes during the annealing and extension steps 32. Specificity of hilA gene primers for Salmonella genus in general and specificity of $f l i \mathrm{C}$ and $s d f$ genes primers for serovar Typhimurium and serovar Enteritidis, respectively, were demonstrated previously by testing 15 different Salmonella serotypes and 16 non-Salmonella bacteria strains ${ }^{26}$. In order to improve the amplification efficiency, surface probes with a length of 45 to 80 bps having a short overhang at the $5^{\prime}$ end were reported as ideal for SP-PCR. The recommended density of such probe for immobilization on the surface was $1.5 \times 10^{11}$ molecules $/ \mathrm{mm}^{2}{ }^{32}$. The length of surface probes used in this study was 60 bps. These lengthy probes may interact non-specifically with fluorophore labelled reverse primers as soon as the reaction mixture reaches room temperature after the reaction. On the other hand, fluorophore labelled reverse primers may also adhere to the polymer SAF surfaces as a result of weak hydrophobic interactions. Possibility of interference from traces of blood matrix components co-concentrated along with the magnetic beads may not be neglected. These unintended possibilities may increase the background fluorescence resulting in chances of false positive signals unless stringent post PCR washing steps are not applied. Therefore, a stable washing step was optimized in this study starting sequentially 
with 1x SSC buffer followed by $1 x$ SSC buffer containing $0.1 \%$ Tween-20 and finally with Milli-Q water (Figure S6). As a result, there was a considerable improvement in the S/N ratio (Figure S7).

Ultra-sensitive detection of Salmonella subtypes in the spiked blood samples. The magnetic bead integrated SP-PCR method after optimization was used to test volunteer human blood samples spiked with different concentrations of $S$. Typhimurium and $S$. Enteritidis. It was possible to detect $S$. Typhimurium and $S$. Enteritidis at a concentration as low as $86 \mathrm{CFU} / \mathrm{mL}$ and $94 \mathrm{CFU} / \mathrm{mL}$, respectively, in the blood (Figure $4 \mathrm{a}$ and $4 \mathrm{~b}$ ). The total time of analysis was $<3 \mathrm{hrs}$ that includes 5 min for selective blood cell lysis, $40 \mathrm{~min}$ for pathogen capturing and magnetic concentration, $\sim 5 \mathrm{~min}$ for sample loading in to the ready-to-use chip and sealing, $50 \mathrm{~min}$ for SP-PCR, $\sim 5-7 \mathrm{~min}$ for chip washing after SP-PCR, 10-15 min for scanning and image acquisition and additional $15 \mathrm{~min}$ in total for preparations between the steps. A significant increase in the $\mathrm{S} / \mathrm{N}$ ration was observed with bacterial concentrations (Figure 4c), although, there were variations in the $\mathrm{S} / \mathrm{N}$ ratio between the target genes at each concentration.

The variations in the $\mathrm{S} / \mathrm{N}$ ratio could be attributed to the difference in hybridization efficiencies among targets as the amplicons of liquid phase reaction (Figure 3d) that serve as template for SP-PCR was dissimilar in size. In this study, it was found that SP-PCR was more than 10 fold sensitive than direct PCR combined with magnetic bead based sample concentration in blood samples. The higher sensitivity achieved with SP-PCR was the cumulative effects of magnetic bead based efficient pathogen concentration and sample purification as well as the excellent light collection efficiency of SAF microlens arrays and higher tolerance of solid phase amplification probes to blood matrix inhibitors. These results justify the potential of magnetic bead based sample concentration combined SP-PCR approach for the highly sensitive detection of invasive pathogens with possible multiplexing capabilities without significant interference.

\section{CONCLUSIONS}

The combination of pathogen concentration and direct PCR strategy was presented in this study as a novel approach for the detection of $S$. Typhimurium and $S$. Enteritidis directly from spiked blood samples without bacterial culturing, DNA isolation and purification steps. The use of magnetic beads in combination with the direct PCR had highly acceptable and reproducible SP-PCR efficiency. In contrast to the conventional direct PCR, the method enabled rapid and ultra-sensitive detection of $S$. Typhimurium 
and $S$. Enteritidis at concentrations as low as $86 \mathrm{CFU} / \mathrm{mL}$ and $94 \mathrm{CFU} / \mathrm{mL}$ respectively in the blood within 3 hrs. The high precision achieved in this integrated immuno-magnetic SP-PCR approach as a result of excellent light collection efficiency of SAF microlens arrays and higher tolerance of solid phase amplification probes to blood matrix inhibitors signifies the potential to overcome the interference from blood matrix in the detection of pathogens in a multiplexed configuration. This integrated method also possesses potential to be used by the food industries and regulatory agencies for the detection of other pathogens to monitor food quality. The combined approach is also ideally suitable for the integration into a Lab-on-a-chip based biosensor system in future for rapid monitoring of pathogens in various biological samples without significant interferences.

\section{Supporting Information}

Supporting Information contains detailed experimental section, Current techniques available/reported for the detection of pathogens (Table S1), sequences of probes and primers for bacterial detection (Table S2), studies on the effects of blood lysing agents on the bacterial viability (Table S3), and supporting figures.

\section{AUTHOR INFORMATION}

Corresponding authors

*Email: viaa@food.dtu.dk, vinayaka_aaydha@yahoo.com,awol@dtu.dk

Tel: +4535886346, +4545256305

\section{Notes}

All authors have given approval to the final version of the manuscript. The authors declare no competing financial interest.

\section{Acknowledgements}

This work was financially supported by the European Union's Horizon 2020 research and innovation program under the project SMARTDIAGNOS, grant agreement No. 687697. Dr. Vinayaka A.C is greatly thankful to the European Union and the Technical University of Denmark for the H.C. Ørsted fellowship 
co-funded under Marie Skłodowska-Curie Actions, grant agreement No. 609405 (FP7) and 713683 (H2020).

\section{REFERENCES}

(1) Goto, M.; Al-Hasan, M. N. Overall Burden of Bloodstream Infection and Nosocomial Bloodstream Infection in North America and Europe. Clin. Microbiol. Infect. 2013, 19 (6), 501509.

(2) Andrews, J. R.; Ryan, E. T. Diagnostics for Invasive Salmonella Infections: Current Challenges and Future Directions. Vaccine 2015, 33 (S3), C8-C15.

(3) Ao, T. T.; Feasey, N. A.; Gordon, M. A.; Keddy, K. H.; Angulo, F. J.; Crump, J. A. Global Burden of Invasive Nontyphoidal Salmonella Disease, 2010. Emerg. Infect. Dis. 2015, 21 (6), 941-949.

(4) Haselbeck, A. H.; Panzner, U.; Im, J.; Baker, S.; Meyer, C. G.; Marks, F. Current Perspectives on Invasive Nontyphoidal Salmonella Disease. Curr. Opin. Infect. Dis. 2017, 30 (5), 498-503.

(5) Phu Huong Lan, N.; Le Thi Phuong, T.; Nguyen Huu, H.; Thuy, L.; Mather, A. E.; Park, S. E.; Marks, F.; Thwaites, G. E.; Van Vinh Chau, N.; Thompson, C. N.; et al. Invasive Non-Typhoidal Salmonella Infections in Asia: Clinical Observations, Disease Outcome and Dominant Serovars from an Infectious Disease Hospital in Vietnam. PLoS Negl. Trop. Dis. 2016, 10 (8), 1-13.

(6) Lopes, A. L. K.; Cardoso, J.; dos Santos, F. R. C. C.; Silva, A. C. G.; Stets, M. I.; Zanchin, N. I. T.; Soares, M. J.; Krieger, M. A. Development of a Magnetic Separation Method to Capture Sepsis Associated Bacteria in Blood. J. Microbiol. Methods 2016, 128 (July), 96-101.

(7) Afshari, A.; Schrenzel, J.; Ieven, M.; Harbarth, S. Bench-to-Bedside Review: Rapid Molecular Diagnostics for Bloodstream Infection - a New Frontier? Crit. Care 2012, 16 (3).

(8) Vinayaka, A. C.; Ngo, T. A.; Kant, K.; Engelsmann, P.; Dave, V. P.; Shahbazi, M.-A.; Wolff, A.; Bang, D. D. Rapid Detection of Salmonella enterica in Food Samples by a Novel Approach with Combination of Sample Concentration and Direct PCR. Biosens. Bioelectron. 2019, 129, 224230. 
(9) Zhu, Y.; Qiao, L.; Prudent, M.; Bondarenko, A.; Gasilova, N.; Möller, S. B.; Lion, N.; Pick, H.; Gong, T.; Chen, Z.; et al. Sensitive and Fast Identification of Bacteria in Blood Samples by Immunoaffinity Mass Spectrometry for Quick BSI Diagnosis. Chem. Sci. 2016, 7 (5), 2987-2995.

(10) Hung, T. Q.; Chin, W. H.; Sun, Y.; Wolff, A.; Bang, D. D. A Novel Lab-on-Chip Platform with Integrated Solid Phase PCR and Supercritical Angle Fluorescence (SAF) Microlens Array for Highly Sensitive and Multiplexed Pathogen Detection. Biosens. Bioelectron. 2017, 90 (October 2016), 217-223.

(11) Hung, T. Q.; Sun, Y.; Poulsen, C. E.; Linh-Quyen, T.; Chin, W. H.; Bang, D. D.; Wolff, A. Miniaturization of a Micro-Optics Array for Highly Sensitive and Parallel Detection on an Injection Moulded Lab-on-a-Chip. Lab Chip 2015, 15 (11), 2445-2451.

(12) Kant, K.; Ngo, T. A.; Matteucci, M.; Wolff, A. Fabrication of 3D Microstructure Array on Chip for Rapid Pathogen Detection. Sensors Actuators, B Chem. 2019, 281 (October 2018), 774-782.

(13) Data, P. P.; Examiner, P.; Alejandro, R.; Laurentano, A. A. (12) United States Patent. 2009, 2 (12).

(14) Bissinger, R.; Modicano, P.; Alzoubi, K.; Honisch, S.; Faggio, C.; Abed, M.; Lang, F. Effect of Saponin on Erythrocytes. Int. J. Hematol. 2014, 100 (1), 51-59.

(15) Rossmanith, P.; Süß, B.; Wagner, M.; Hein, I. Development of Matrix Lysis for Concentration of Gram Positive Bacteria from Food and Blood. J. Microbiol. Methods 2007, 69 (3), 504-511.

(16) Schneider, C. A.; Rasband, W. S.; Eliceiri, K. W. NIH Image to ImageJ: 25 Years of Image Analysis. Nat. Methods 2012, 9 (7), 671-675.

(17) Shrivastava, A.; Gupta, V. Methods for the Determination of Limit of Detection and Limit of Quantitation of the Analytical Methods. Chronicles Young Sci. 2011, 2 (1), 21.

(18) Hermanson, G. T. Immobilization of Ligands on Chromatography Supports. In Bioconjugate Techniques; Academic Press publications, 2013; pp 589-740.

(19) Monteiro, L.; Bonnemaison, D.; Vekris, A.; Petry, K. G.; Bonnet, J.; Vidal, R.; Cabrita, J.; 
Mégraud, F. Complex Polysaccharides as PCR Inhibitors in Feces: Helicobacter Pylori Model. $J$. Clin. Microbiol. 1997, 35 (4), 995-998.

(20) López-García, P.; Knapp, S.; Ladenstein, R.; Forterre, P. In Vitro DNA Binding of the Archaeal Protein Sso7d Induces Negative Supercoiling at Temperatures Typical for Thermophilic Growth. Nucleic Acids Res. 1998, 26 (10), 2322-2328.

(21) Schrader, C.; Schielke, A.; Ellerbroek, L.; Johne, R. PCR Inhibitors - Occurrence, Properties and Removal. J. Appl. Microbiol. 2012, 113 (5), 1014-1026.

(22) Hedman, J.; Knutsson, R.; Ansell, R.; Rådström, P.; Rasmusson, B. Pre-PCR Processing in Bioterrorism Preparedness: Improved Diagnostic Capabilities for Laboratory Response Networks. Biosecurity Bioterrorism Biodefense Strateg. Pract. Sci. 2013, 11 (S1), S87-S101.

(23) Opel, K. L.; Chung, D.; McCord, B. R. A Study of PCR Inhibition Mechanisms Using Real Time PCR. J. Forensic Sci. 2010, 55 (1), 25-33.

(24) Sidstedt, M.; Hedman, J.; Romsos, E. L.; Waitara, L.; Wadsö, L.; Steffen, C. R.; Vallone, P. M.; Rådström, P. Inhibition Mechanisms of Hemoglobin, Immunoglobulin G, and Whole Blood in Digital and Real-Time PCR. Anal. Bioanal. Chem. 2018, 410 (10), 2569-2583.

(25) Zijlstra, W. G.; Buursma, A. Spectrophotometry of Hemoglobin: Absorption Spectra of Bovine Oxyhemoglobin, Deoxyhemoglobin, Carboxyhemoglobin, and Methemoglobin. Comp. Biochem. Physiol. - B Biochem. Mol. Biol. 1997, 118 (4), 743-749.

(26) Chin, W. H.; Sun, Y.; Høgberg, J.; Quyen, T. L.; Engelsmann, P.; Wolff, A.; Bang, D. D. Direct PCR - A Rapid Method for Multiplexed Detection of Different Serotypes of Salmonella in Enriched Pork Meat Samples. Mol. Cell. Probes 2017, 32, 24-32.

(27) O'Regan, E.; McCabe, E.; Burgess, C.; McGuinness, S.; Barry, T.; Duffy, G.; Whyte, P.; Fanning, S. Development of a Real-Time Multiplex PCR Assay for the Detection of Multiple Salmonella Serotypes in Chicken Samples. BMC Microbiol. 2008, 8, 1-11.

(28) Hadjinicolaou, A. V.; Demetriou, V. L.; Emmanuel, M. A.; Kakoyiannis, C. K.; Kostrikis, L. G. Molecular Beacon-Based Real-Time PCR Detection of Primary Isolates of Salmonella 17 
Typhimurium and Salmonella Enteritidis in Environmental and Clinical Samples. BMC Microbiol. 2009, 9, 1-14.

(29) Ogunremi, D.; Nadin-Davis, S.; Dupras, A. A.; Márquez, I. G.; Omidi, K.; Pope, L.; Devenish, J.; Burke, T.; Allain, R.; Leclair, D. Evaluation of a Multiplex Pcr Assay for the Identification of Salmonella Serovars Enteritidis and Typhimurium Using Retail and Abattoir Samples. J. Food Prot. 2017, 80 (2), 295-301.

(30) Azinheiro, S.; Carvalho, J.; Prado, M.; Garrido-Maestu, A. Evaluation of Different Genetic Targets for Salmonella enterica Serovar Enteriditis and Typhimurium, Using Loop-Mediated Isothermal AMPlification for Detection in Food Samples. Front. Sustain. Food Syst. 2018, 2 (February), 1-8.

(31) Agron, P. G.; Walker, R. L.; Kinde, H.; Sawyer, S. J.; Hayes, D. C.; Wollard, J.; Andersen, G. L. Identification by Subtractive Hybridization of Sequences Specific for Salmonella enterica Serovar Enteritidis. Appl. Environ. Microbiol. 2001, 67 (3-12), 4984-4991.

(32) Chin, W. H.; Sun, Y.; Høgberg, J.; Hung, T. Q.; Wolff, A.; Bang, D. D. Solid-Phase PCR for Rapid Multiplex Detection of Salmonella Spp. at the Subspecies Level, with Amplification Efficiency Comparable to Conventional PCR. Anal. Bioanal. Chem. 2017, 409 (10), 2715-2726.

\section{Figures legend}

Scheme 1. Schematic representation of the magnetic bead based sample concentration combined SPPCR. (A) Selective blood cell lysis, (A1) Infected blood before lysis, (A2) Infected blood after lysis, (B) Antibody immobilized protein AG magnetic bead, (C) Magnetically captured Salmonella cell, (D) SP-PCR and optical detection, (D1) SAF embedded microchip, (D2) SAF micro-lens array, (D3) Target specific amplification on SAF structures, (D4) Image capture after amplification

Figure 1. Direct PCR linear curve after concentrating Salmonella Typhimurium and Salmonella Enteritidis from PBS with magnetic beads. 
Figure 2. SEM image of the SAF micro-array and polymer microchip. (a) SAF arrays, (b) Truncated cone shaped SAF structure, (c) Polymer microchip with 4 reaction chambers.

Figure 3. Multiplexed detection of Typhimurium and Enteritidis concentrated from PBS using magnetic beads. (a) Pattern of spotting of target probe on the SAF arrays, (b) SP-PCR of Enteritidis, (c) SP-PCR of Typhimurium, (d) Gel electrophoresis image of amplicons in the leftover liquid from SP-PCR reaction, lane 1: Molecular marker, lane 2 and 3: Negative controls, lane 4 and 5: S. Enteritidis, lane 6 and 7: S. Typhimurium.

Figure 4. SP-PCR for multiplexed detection of Typhimurium and Enteritidis concentrated from spiked blood using magnetic beads. (A) Typhimurium, (B) Enteritidis, (C) Comparison of SNR and sensitivity of the SP-PCR amplification of pathogen specific target genes performed on the SAF microlens array in multiplexed configuration. 
Scheme 1. Schematic representation of the magnetic bead based sample concentration combined SP-PCR. (A) Selective blood cell lysis, (A1) Infected blood before lysis, (A2) Infected blood after lysis, (B) Antibody immobilized protein AG magnetic bead, (C) Magnetically captured Salmonella cell, (D) SP-PCR and optical detection, (D1) SAF embedded microchip, (D2) SAF micro-lens array, (D3) Target specific amplification on SAF structures, (D4) Image capture after amplification

$81 \times 59 \mathrm{~mm}(300 \times 300$ DPI $)$ 


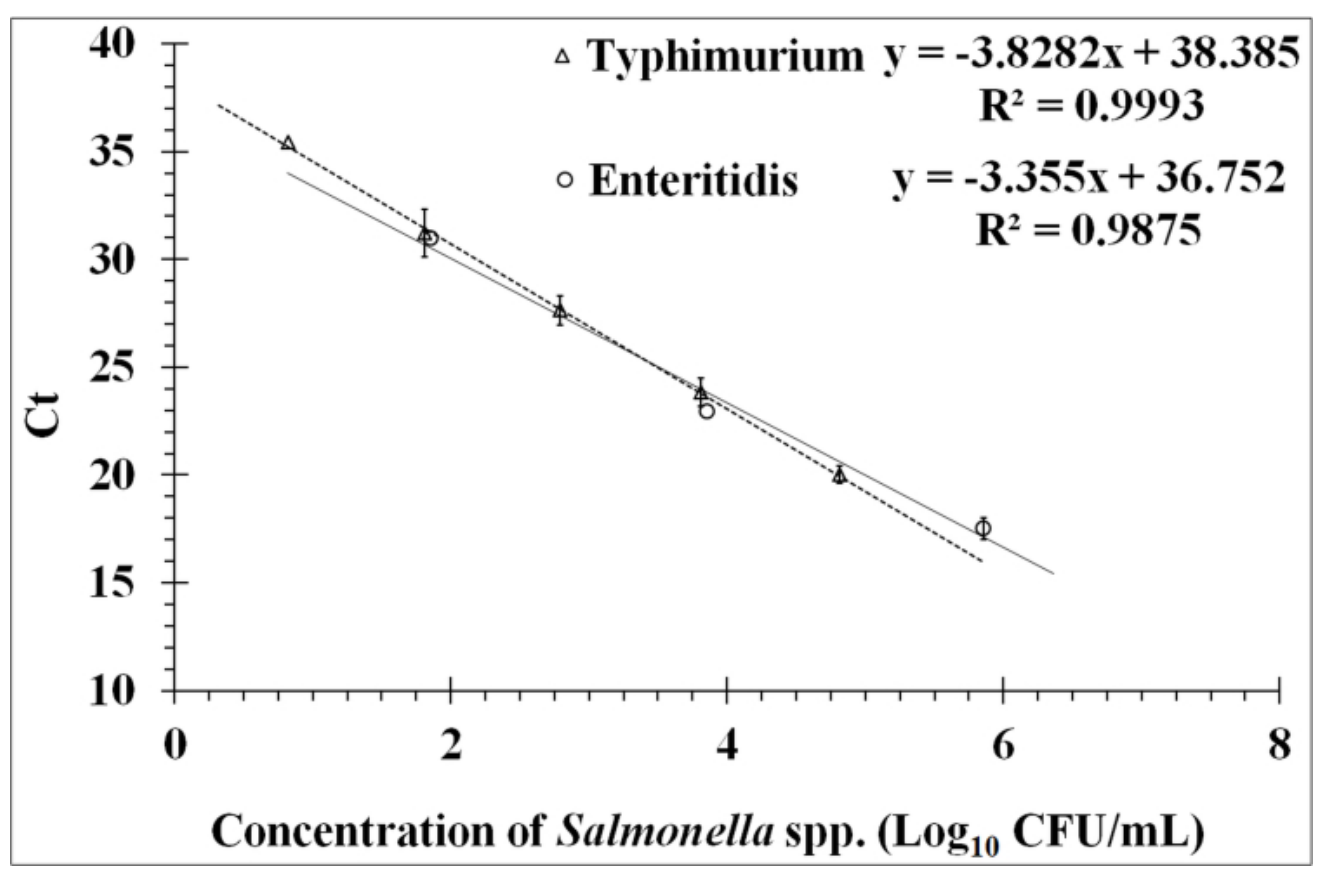

Figure 1. Direct PCR linear curve of S. Typhimurium and S. Enteritidis after concentrating from PBS with magnetic beads.

$63 \times 41 \mathrm{~mm}(300 \times 300 \mathrm{DPI})$ 


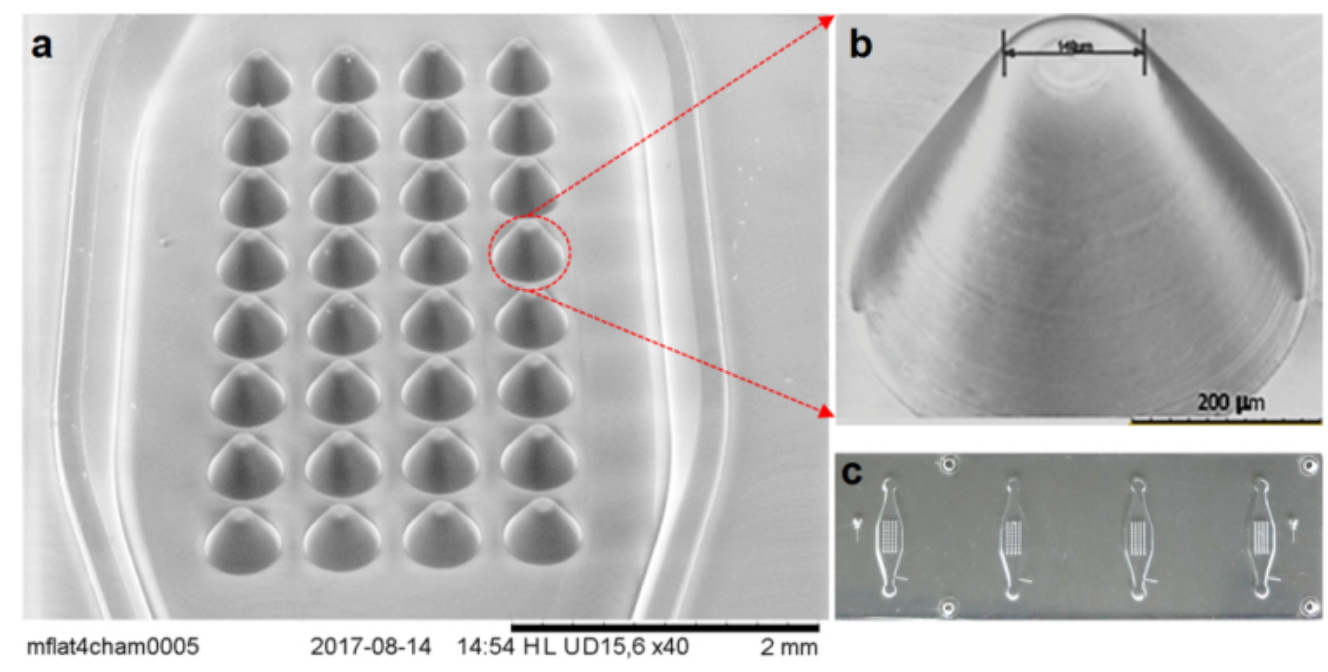

Figure 2. SEM image of the SAF micro-array and polymer microchip. (a) SAF arrays, (b) Truncated cone shaped SAF structure, (c) Polymer microchip with 4 reaction chambers.

\section{$63 \times 31 \mathrm{~mm}(300 \times 300 \mathrm{DPI})$}




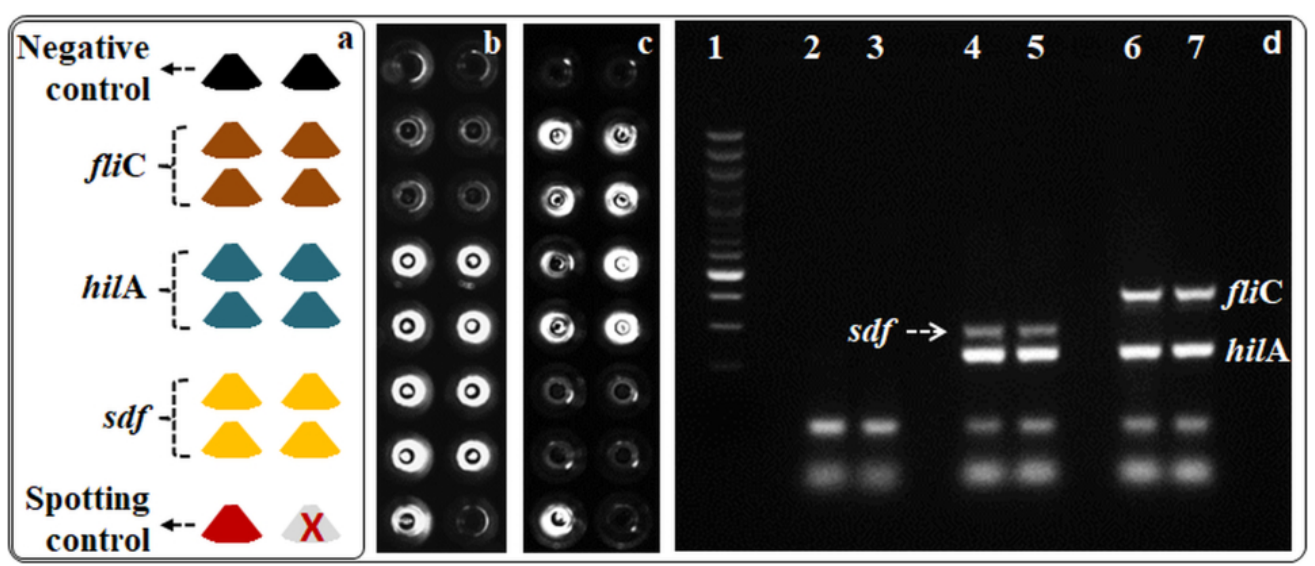

Figure 3. Multiplexed detection of Typhimurium and Enteritidis concentrated from PBS using magnetic beads. (a) Pattern of spotting of target probe on the SAF arrays, (b) SP-PCR of Enteritidis, (c) SP-PCR of Typhimurium, (d) Gel electrophoresis image of amplicons in the leftover liquid from SP-PCR reaction, lane 1: Molecular marker, lane 2 and 3: Negative controls, lane 4 and 5: S. Enteritidis, lane 6 and 7: S. Typhimurium.

$81 \times 34 \mathrm{~mm}(300 \times 300$ DPI $)$ 


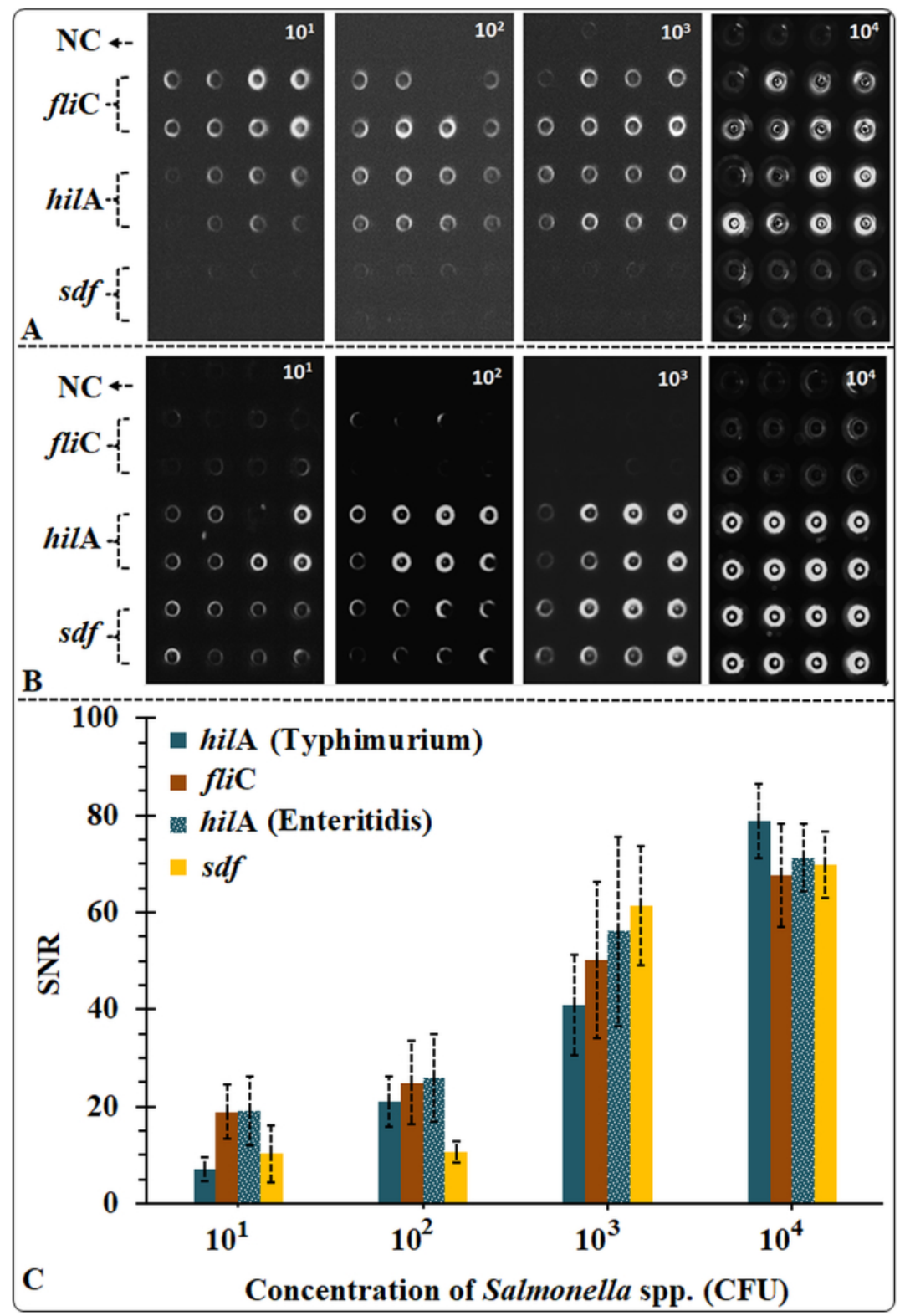

Figure 4. SP-PCR for multiplexed detection of Typhimurium and Enteritidis concentrated from spiked blood using magnetic beads. (A) Typhimurium, (B) Enteritidis, (C) Comparison of SNR and sensitivity of the SPPCR amplification of pathogen specific target genes performed on the SAF microlens array in multiplexed configuration.

\section{$63 \times 93 \mathrm{~mm}(300 \times 300 \mathrm{DPI})$}




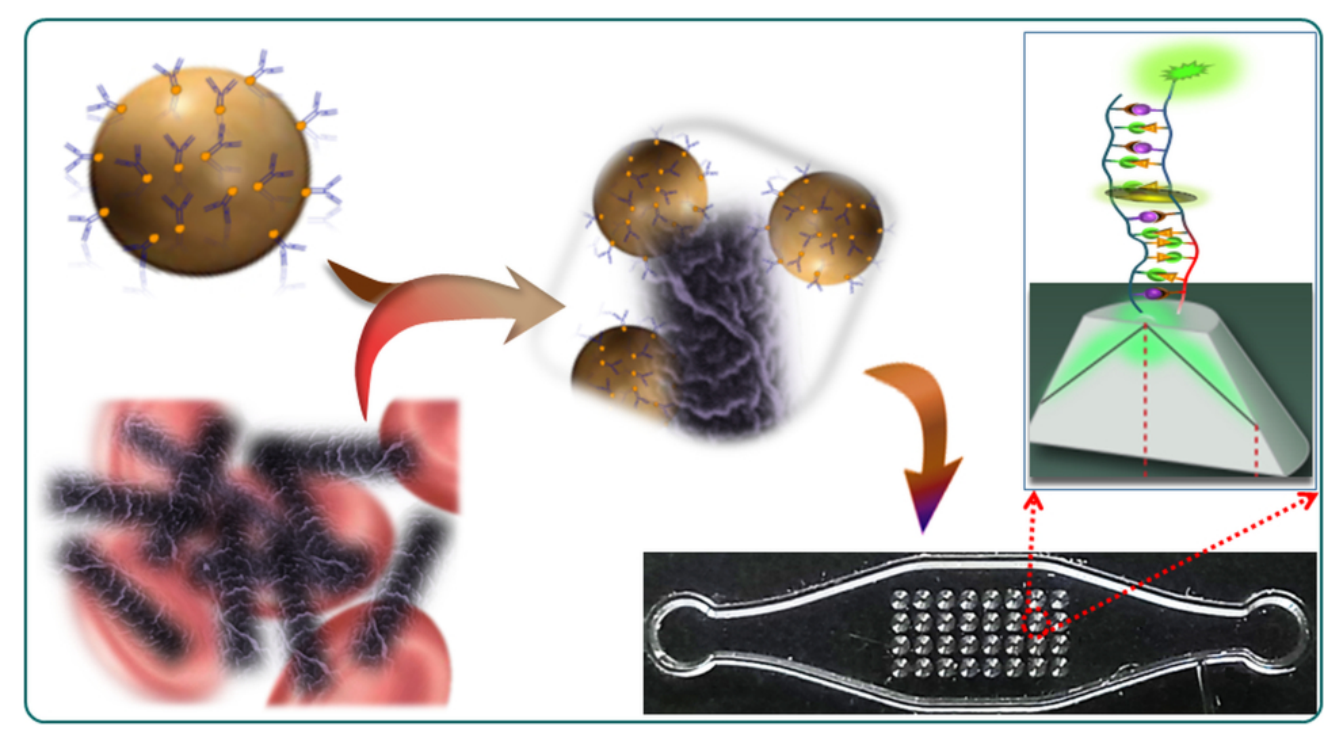

Table of contents artwork

$81 \times 44 \mathrm{~mm}(300 \times 300$ DPI $)$ 